\title{
A comparative study of hourly and daily relationships between selected meteorological parameters and airborne fungal spore composition
}

\author{
Agnieszka Grinn-Gofroń • Beata Bosiacka • Aleksandra Bednarz • \\ Tomasz Wolski
}

Received: 20 January 2017 / Accepted: 6 July 2017/Published online: 19 July 2017

(C) The Author(s) 2017. This article is an open access publication

\begin{abstract}
Air sampling was conducted in Szczecin (Poland) throughout April-September 2013. The final data set included 177 daily and 4248 hourly samples. The total of 21 types of spores, which occurred in a number $>10$ in the season, were taken into account. The following meteorological parameters were analyzed: air temperature, relative humidity, precipitation and wind speed. Effects of individual weather parameters on hourly and daily concentrations of different fungal spore types were examined using Spearman's rank association test, whereas effects of complex of meteorological factors on hourly and daily compositions of spore were assessed using detrended correspondence analysis (DCA) and redundancy analysis (RDA). Airborne fungal spore distribution patterns in relation to meteorological variables were determined by RDA, after DCA results detected a linear structure of the spore data. The RDA results obtained indicated that all the applied variables accounted for 20 and $22 \%$ of the total variance in the hourly and daily spore data, respectively. The results of stepwise forward selection of variables revealed all included hourly and daily
\end{abstract}

\footnotetext{
A. Grinn-Gofroń $(\square) \cdot$ B. Bosiacka · A. Bednarz Department of Plant Taxonomy and Phytogeography, Faculty of Biology, University of Szczecin, Wąska 13, 71-415 Szczecin, Poland

e-mail: agofr@univ.szczecin.pl

T. Wolski

Faculty of Geosciences, University of Szczecin, Mickiewicza 18, 70-383 Szczecin, Poland
}

meteorological variables were statistically significant. The largest amount of the total variance in the spore composition was explained by the air temperature in both cases $(16 \%)$. Multivariate ordination did not show large differences between the hourly and daily relationships (with exception of wind speed impact), while the differences between simple hourly and daily correlations were more clear. Correlations between daily values of variables were in most cases higher than between hourly values of variables.

Keywords Airspora occurrence $\cdot$ Meteorological conditions · Hourly and daily data $\cdot$ Redundancy analysis (RDA)

\section{Introduction}

The spores of many fungi are displaced from their parent colonies by passive mechanisms-by physical disturbance resulting from airflow, raindrops, vibration, or by the specific vectors (e.g., insects and birds). Active mechanisms of spore discharge are powered by hydrostatic pressure, fast movements induced by cytoplasmic dehydration, and by the utilization of surface tension force. The active mechanisms of spore discharge are depended on the taxonomical group. In cases of Ascomycota, the ascus is essentially an explosive sporangium-the asci are pressurized osmotically and spores and droplets of epiplasmic 
fluid are vigorously ejected. Most Basidiomycota utilize the process of ballistospore discharge, which is powered by the rapid motion of a fluid droplet over the spore surface (Ingold 1971, 1999; Pringle et al. 2005).

The function of spore discharge is to free spores, which may subsequently be dispersed. Most of the spores appears in the air, where they will remain for a longer or shorter period of time and are moved to different distances. When spores are puffed and splashed from the surfaces of their colonies by rain water drops, the impact of raindrops exerts much larger forces on colonies than wind disturbance. Spores can be thrown over short distances or can be carried over longer distances by wind as free spores or associated with water droplets. Dispersal can occur a distance from a few centimeters to hundreds of kilometers, even between continents (Ingold 1971; Carlile et al. 2001).

Spore production, release and spread are elements of the whole life cycle of fungi, determined by inherent characteristic of the fungi, availability of substrates, temperature, moisture (from rain and humidity) and other environmental factors. Many fungi are mesophilic. Sporulation process takes place in a narrower range of temperatures than vegetative growth. Moreover, changes in temperature over short time intervals can affect the degree of thermal turbulence, which simultaneously dilute spore concentrations at ground level, and cause the release of more spores by mechanical disturbance (Ingold 1971; Money 2015).

The growth of most fungi is favoured by high moisture, and active mechanisms of spore discharge are also related to the availability of water. Many species of Ascomycota and Basidiomycota are actively wet spore discharging fungi. At high relative humidity, they activate discharge mechanism by hygroscopic uptake of water vapor. Dry spore discharging fungi release spores by the flow of air or by hygroscopic twisting movement, which occurs upon drying. Such spores are mostly emitted when dry, warm and windy conditions prevail (Meredith 1963; Lacey 1986; Elbert et al. 2007).

The impact of precipitation on the spore content in the air may be twofold: on the one hand raindrops may cause release of fungal spores; on the other hand the rain can remove fungal spores by rain-out and washout effects (Ingold 1971; Lacey 1986).
As a consequence of the types of factors affecting the release of spores and their further spread, spore occurrence in the air is determined by, among others, several interacting meteorological factors. It is important and useful (e.g., public health, agriculture, horticulture and forestry, aerobiology) to know how changes in the spore concentration and composition in the air come with changes in weather conditions, including complex of variables. Such complex interactions have been analyzed in a few studies, which considered only daily values of variables (Hjelmroos 1993; Li and Kendrick 1994, 1995; Grinn-Gofroń and Bosiacka 2015; Sadyś et al. 2015).

The aim of this study was to analyze and compare the impact of meteorological parameters on daily and hourly concentrations and compositions of fungal spores during 1 year of the study, and to pinpoint the most crucial weather parameters that are useful to describe a daily and hourly compositions of fungal spores in the air.

\section{Materials and methods}

Aerobiological study was carried out in Szczecin when the occurrence of spores in the air was the highest (from 1 April to 30 September) in 2013. The 6-day gaps in the data set resulted from technical problems (power outage) during taking samples. Sampling took place by volumetric method (Hirst 1952) according to the recommendations of the British Aerobiology Federation (1995) and preparation and evaluation of samples based on Frenguelli (2003). Both methods were described in detail in GrinnGofroń and Bosiacka (2015).

We took into account 21 types of spores, which occurred in a number $<10$ in the season, and that we were able to identify at the level of genus (type): Agrocybe, Alternaria, Chaetomium, Cladosporium, Coprinus, Curvularia, Didymella, Drechslera type, Epicoccum, Fusarium, Ganoderma, Leptosphaeria type, Periconia, Phaeosphaeria, Pithomyces, Pleospora, Polythrincium, Stachybotrys, Stemphylium, Tilletia, Torula.

The meteorological parameters taken into consideration in assessment of the effect of meteorological conditions on the airborne fungal spores were: TEMP - hourly air temperature and daily mean temperature $\left({ }^{\circ} \mathrm{C}\right), \mathrm{RH}$ - hourly relative humidity and daily 
mean relative humidity (\%), PRECIP-hourly and daily amount of precipitation (mm), WIND—hourly wind velocity and daily mean wind velocity $\left(\mathrm{m} \mathrm{s}^{-1}\right)$.

Minimum, maximum and mean values of selected meteorological parameters during the sampling period (01.04.-30.09.2013) in Szczecin are presented in Table 1.

\subsection{Data analysis}

Normality of the variables was tested with the commonly used Kolmogorov-Smirnov and Chisquare tests. Since most of the data did not fit the normal distribution $(p<0.05)$, the Spearman's rank association test was applied to examine effects of selected weather parameters on hourly and daily concentrations of selected airborne fungal spore (STATISTICA StatSoft v. 10.0). Effects of complex of weather parameters on hourly and daily composition of fungal spore were assessed using the software package CANOCO v. 4.5 (ter Braak and Šmilauer 2002), after log transformation of spore and meteorological data by a modified formula available in CANOCO: $Y_{k i}^{*}=\log \left(A y_{k i}+B\right)$, where $y_{k i}$ is the concentration of $k$ spores in $i$ sample; the coefficients $A$ and $B$ are standard set as 1 . Airborne fungal spore distribution patterns in relation to meteorological variables were determined by multivariate redundancy analysis (RDA), after detrended correspondence analysis (DCA) results detected a linear structure of the spore data. Detailed information about the applied multivariate methods, stepwise forward selection and tests of significance is available in Grinn-Gofron and Bosiacka (2015).

Redundancy among the meteorological variables was explored with the variance inflation factor (VIF). VIF analysis (available in CANOCO) is a diagnostic tool used to identify useless constrains. The large value of variance inflation factor (VIF $>20$ ) mean that a given variable is so strongly correlated with others, that the rate of the canonical variable is unstable and not suitable to interpret.

\section{Results}

The results of Spearman's rank association test (Table 2) clearly showed the impact of individual meteorological parameters on the concentration of different spore types and they are supplementary to the results computed by multivariate analysis RDA provides both a comprehensive assessment of the impact of complex of meteorological parameters on specific spore composition in the air, as well as illustrates the correlation between the occurrence of particular spore types and meteorological variables. Individual dependences, visible on the RDA diagrams (Fig. 1a, b), generally corresponded to the strength and direction of the correlation in both types of analyses. However, multivariate ordination does not show large differences between the hourly and daily relationships, while the differences between simple hourly and daily correlations were more clear. Correlations between daily values of variables were in most cases higher than between hourly values of variables. The hourly relationships, due to the much higher number of samples (4248 hourly samples and 177 daily samples), were statistically significant in a larger number of cases (even very weak correlations were statistically significant).

After removing the dew point temperature (DP) from the data set (as they VIF scored above 400), the other meteorological variables did not show autocorrelation (Table 3).

Indirect ordination analyses (DCA) was made to check the data structure. DCA results revealed that the gradient length represented by the first ordination axis was lower than $3 \mathrm{SD}$ (standard deviation), both in hourly and daily data set $(2.790$ and 1.470 , respectively). This corresponds to a linear data structure,

Table 1 Values of selected meteorological parameters during the sampling period (01.04.-30. 09.2013) in Szczecin

\begin{tabular}{lccc}
\hline Meteorological parameters & Min. value & Max. value & Mean value \\
\hline Air temperature $\left({ }^{\circ} \mathrm{C}\right)$ & -2 & 38 & 18.5 \\
Relative humidity (\%) & 9 & 100 & 72.6 \\
Precipitation $(\mathrm{mm})$ & 0 & 24 & 0.2 \\
Wind velocity $\left(\mathrm{m} \mathrm{s}^{-1}\right)$ & 0 & 4 & 0.1 \\
\hline
\end{tabular}


Table 2 Contribution of spores and the results of Spearman's rank correlation test between hourly and daily concentrations of fungal spores and meteorological parameters

\begin{tabular}{|c|c|c|c|c|c|c|c|c|c|c|}
\hline \multirow[t]{2}{*}{ Taxon } & \multicolumn{2}{|c|}{$\begin{array}{l}\text { Seasonal } \\
\text { contribution }\end{array}$} & \multicolumn{2}{|l|}{ Temp } & \multicolumn{2}{|l|}{ RH } & \multicolumn{2}{|l|}{ Wind } & \multicolumn{2}{|l|}{ Precip } \\
\hline & Count & $\%$ & Hourly & Daily & Hourly & Daily & Hourly & Daily & Hourly & Daily \\
\hline Agrocybe & 28 & 0.005 & 0.005 & 0.071 & $0.063 *$ & $0.165^{*}$ & 0.029 & $-0.224 *$ & -0.024 & -0.080 \\
\hline Alternaria & 8648 & 1.586 & $0.359 *$ & $0.480 *$ & $-0.100 *$ & -0.093 & $0.091^{*}$ & -0.152 & $-0.078^{*}$ & $-0.200^{*}$ \\
\hline Chaetomium & 108 & 0.020 & $0.049 *$ & $0.215^{*}$ & $0.085^{*}$ & 0.152 & -0.026 & $-0.288^{*}$ & -0.030 & -0.048 \\
\hline Cladosporium & 346135 & 63,493 & $0.511 *$ & $0.601 *$ & $-0.075^{*}$ & -0.072 & $0.121 *$ & -0.152 & $-0.070 *$ & -0.084 \\
\hline Coprinus & 22 & 0.004 & 0.006 & 0.069 & -0.013 & -0.066 & -0.012 & -0.026 & 0.018 & 0.068 \\
\hline Curvularia & 19 & 0.003 & -0.009 & -0.020 & $0.047 *$ & $0.262^{*}$ & 0.008 & -0.123 & $0.041^{*}$ & $0.166^{*}$ \\
\hline Didymella & 175,316 & 32,159 & $0.069 *$ & $0.268^{*}$ & $0.057 *$ & -0.012 & 0.025 & -0.072 & 0.002 & 0.051 \\
\hline Drechslera type & 856 & 0.157 & $0.218 *$ & $0.525^{*}$ & $-0.099 *$ & $-0.172 *$ & 0.022 & -0.066 & -0.021 & -0.106 \\
\hline Epicocсum & 1413 & 0.260 & $0.162 *$ & $0.169^{*}$ & $-0.077 *$ & -0.038 & $0.033^{*}$ & $-0.205^{*}$ & $-0.042^{*}$ & -0.112 \\
\hline Fusarium & 30 & 0.006 & $-0.083 *$ & 0.046 & $0.181 *$ & $0.294 *$ & $0.064 *$ & -0.081 & $0.094 *$ & $0.205^{*}$ \\
\hline Ganoderma & 3586 & 0.658 & $0.179 *$ & $0.529 *$ & $0.183^{*}$ & -0.086 & -0.032 & $-0.325^{*}$ & -0.027 & $-0.201^{*}$ \\
\hline Leptosphaeria type & 7112 & 1.305 & $0.110^{*}$ & 0.138 & $0.198 *$ & 0.130 & -0.026 & 0.125 & -0.025 & $0.416^{*}$ \\
\hline Periconia & 28 & 0.005 & $0.086^{*}$ & $0.182 *$ & $-0.057 *$ & -0.035 & $0.047 *$ & 0.014 & -0.027 & 0.010 \\
\hline Phaeosphaeria & 448 & 0.082 & $0.052 *$ & 0.082 & $0.164 *$ & $0.248^{*}$ & 0.005 & -0.179 & $0.035^{*}$ & $0.205^{*}$ \\
\hline Pithomyces & 76 & 0.014 & $0.074 *$ & 0.139 & -0.026 & -0.037 & 0.025 & -0.078 & -0.019 & 0.006 \\
\hline Pleospora & 715 & 0.131 & $0.083 *$ & $0.217^{*}$ & -0.011 & $0.183^{*}$ & $0.044^{*}$ & -0.065 & 0.001 & $0.164 *$ \\
\hline Polythrincium & 31 & 0.006 & $0.119 *$ & $0.398 *$ & $-0.066^{*}$ & -0.146 & $0.037 *$ & -0.117 & $-0.040^{*}$ & $-0.185^{*}$ \\
\hline Stachybotrys & 11 & 0.001 & $-0.052 *$ & $-0.215^{*}$ & 0.020 & 0.138 & -0.014 & -0.056 & 0.022 & 0.025 \\
\hline Stemphylium & 77 & 0.014 & $-0.037^{*}$ & -0.095 & 0.011 & -0.013 & 0.019 & -0.015 & 0.019 & $0.300^{*}$ \\
\hline Tilletia & 33 & 0.006 & $0.107 *$ & $0.321 *$ & $-0.066^{*}$ & $-0.350 *$ & -0.031 & -0.017 & 0.002 & $-0.210^{*}$ \\
\hline Torula & 463 & 0.085 & $0.098 *$ & $0.301 *$ & $-0.083^{*}$ & $-0.400 *$ & -0.016 & 0.031 & -0.029 & $-0.194^{*}$ \\
\hline
\end{tabular}

$* p<0.05$

therefore the direct redundancy analyses (RDA) were used to determine functional relationship between composition of airspora and meteorological factors. The RDA results obtained indicated that all the applied variables (excluding DP) accounted for 20 and $22 \%$ of the total variance in the hourly and daily spore data, respectively (Table 4). First axis and all canonical axes were significant in both cases as tested by the unrestricted Monte Carlo permutation test ( $p=0.002)$.

The results of stepwise forward selection of variables revealed all included hourly and daily meteorological variables (TEMP, RH, PRECIP and WIND) were statistically significant $(p \leq 0.05)$. The largest amount of the total variance in the spore composition was explained by the TEMP in both cases (16\%) (Table 5).

Distribution of particular fungal spore types along meteorological gradients differed only in detail between hourly and daily data (Fig. 1a, b). Following the gradient of increasing temperature of the air, the maximum abundance of Cladosporium spores (hourly data), and additionally Ganoderma spores (daily data) was related to the highest TEMP values, whereas the occurrence of spores of Phaeosphaeria, Agrocybe, Leptosphaeria type, Fusarium (hourly data) and additionally Curvularia, Stachybotrys and Stemphylium (daily data) - to the lowest values. Other fungal spores occurred most numerous at moderate values of the air temperature.

Individual relationships, visible on the RDA diagram (Fig. 1a, b), in the majority of cases correspond to the results of Spearman's rank correlation test (Table 2). The closest positive relationships were observed between the air temperature and concentrations of Cladosporium and Alternaria spores in the hourly data set $\left(r_{\mathrm{s}}=0.511\right.$ and $r_{\mathrm{s}}=0.359$, respectively), and Cladosporium, Ganoderma, Drechslera type and Alternaria spores in the daily data set $\left(r_{\mathrm{s}}=0.601, r_{\mathrm{s}}=0.529, r_{\mathrm{s}}=0.525\right.$ and $r_{\mathrm{s}}=0.480$, 

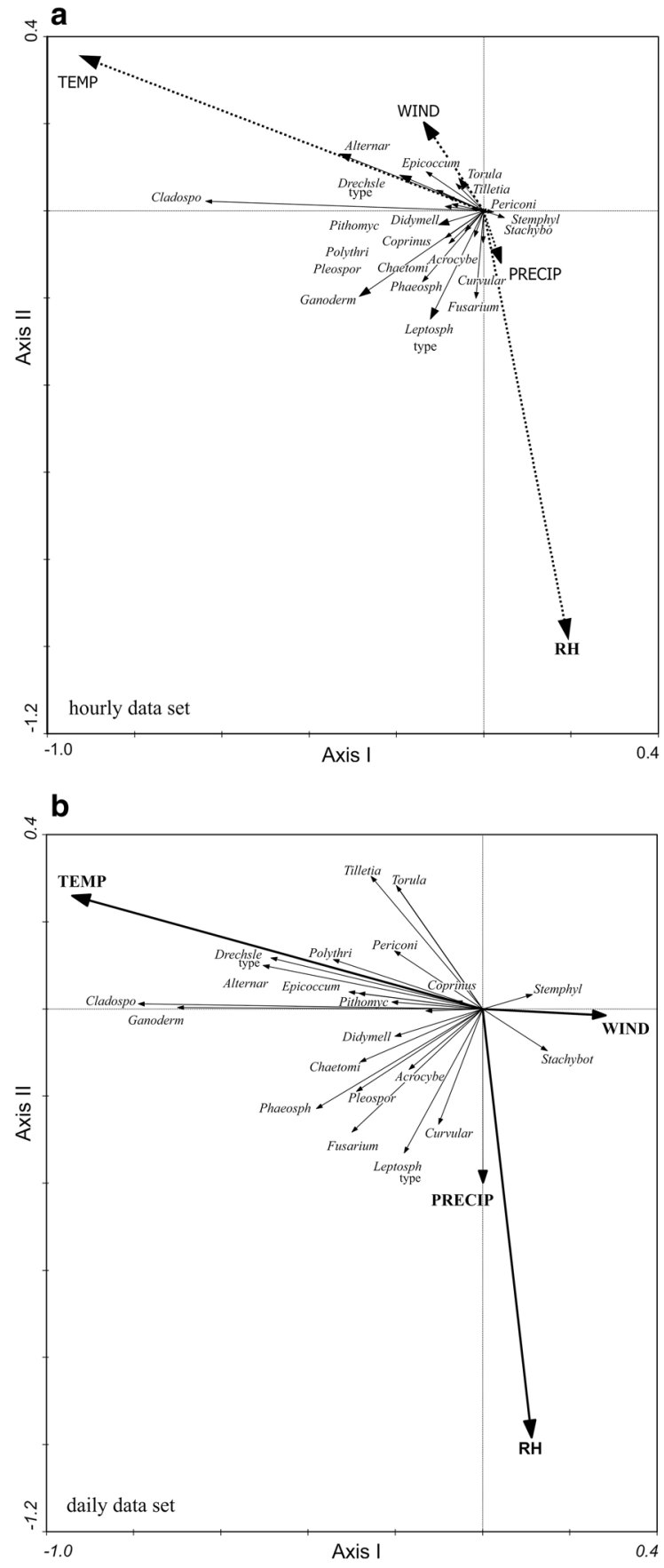

Fig. 1 Diagrams of fungal spores and meteorological variables ordination along the first two RDA axes for hourly (a) and daily (b) samples collected in Szczecin (NW Poland)

respectively). An inversely proportional, statistically significant impact of the air temperature on the concentrations of spores in the hourly data set was observed for Fusarium, Stachybotrys and
Stemphylium; however, all these negative correlations were very weak. The highest, but still weak, negative impact of the air temperature was observed in the daily data set for Stachybotrys spores $\left(r_{\mathrm{s}}=-0.215\right)$.

The second most important meteorological variable impacted fungal spore concentrations was relative humidity of the air. Following the gradient of increasing RH (Fig. 1), the maximum abundance of Leptosphaeria type, Fusarium, Phaeosphaeria and Curvularia spores was related to moderate values of $\mathrm{RH}$ in the hourly and daily data set, whereas the occurrence of Ganoderma spores differed in both data sets (in the hourly data set was associated with the moderate RH values, and in the daily data set was associated with the lowest RH values). The maximum abundance of all other spore types was observed at the lowest RH values in both data sets.

According to the results of Spearman's rank correlation test (Table 2), all statistically significant and directly proportional relationships between $\mathrm{RH}$ and fungal spore concentrations were weak $\left(r_{\mathrm{s}}<0.300\right)$ in both data sets. Negative impact of $\mathrm{RH}$ on the concentrations of spores was slightly stronger only for Tilletia and Torula in the daily data set $\left(r_{\mathrm{s}}=-0.350\right.$ and $r_{\mathrm{s}}=-0.400$, respectively).

The last two meteorological variables, wind speed and precipitation, were statistically significant and explained the smallest amount of the total variance in the fungal spore composition (WIND 1-2\%, PRECIP < 1\%) (Table 5). However, distribution of individual fungal spore types along WIND gradients clearly differed between hourly and daily data set (was almost opposite).

According to the results of Spearman's rank correlation test (Table 2), the highest, but still weak, negative impact of WIND on the concentration of spores was observed for Ganoderma $\left(r_{\mathrm{s}}=-0.325\right)$, and PRECIP-for Tilletia $\left(r_{\mathrm{s}}=-0.210\right)$ in the daily data set. Directly proportional, moderate impact of PRECIP was observed for Leptosphaeria type $\left(r_{\mathrm{s}}=0.416\right)$ in the daily data set (Table 2$)$.

\section{Discussion}

Numerous studies on the effects of environmental factors on the presence of spores in the air are useful in developing predictive models and determining the direction of the spread of spores, what may be important, e.g., public health (allergenic spores), 
Table 3 Redundancy among the meteorological variables with and without dew point temperatute

* Values without dew point temperature

Table 4 Summary of RDA for hourly and daily samples
Table 5 Forward selection results with the test of variable significance for hourly and daily samples

$p \leq 0.05$ (significance level)

\begin{tabular}{lccrrrr}
\hline Variables & (Weighted) mean & \multicolumn{2}{c}{ Standard deviation } & \multicolumn{2}{c}{ Variance inflation factor } \\
\hline TEMP & 10.4237 & $15.2479^{*}$ & 4.6059 & $5.1429^{*}$ & 392.7994 & $1.2262^{*}$ \\
RH & 74.0541 & $74.0541^{*}$ & 11.3110 & $11.3110^{*}$ & 102.4877 & $1.3386^{*}$ \\
WIND & 2.8399 & $2.8399^{*}$ & 1.0518 & $1.0518^{*}$ & 1.1336 & $1.1064^{*}$ \\
PRECIP & 2.3551 & $2.3551^{*}$ & 5.9782 & $5.9782^{*}$ & 1.2119 & $1.2105^{*}$ \\
DP & 15.2479 & - & 5.1429 & - & 457.9960 & - \\
\hline
\end{tabular}

\begin{tabular}{|c|c|c|}
\hline Axis & Hourly & Daily \\
\hline \multicolumn{3}{|l|}{ Eigenvalues } \\
\hline $\mathrm{I}$ & 0.181 & 0.176 \\
\hline II & 0.017 & 0.031 \\
\hline III & 0.001 & 0.014 \\
\hline IV & 0.000 & 0.003 \\
\hline \multicolumn{3}{|l|}{ Spores-environment correlations } \\
\hline I & 0.628 & 0.734 \\
\hline II & 0.404 & 0.547 \\
\hline III & 0.139 & 0.358 \\
\hline IV & 0.063 & 0.313 \\
\hline \multicolumn{3}{|l|}{ Cumulative percentage variance of spore data } \\
\hline I & 18.1 & 17.6 \\
\hline II & 19.8 & 20.8 \\
\hline III & 20.0 & 22.1 \\
\hline IV & 20.0 & 22.4 \\
\hline \multicolumn{3}{|c|}{ Cumulative percentage variance of spores-environment relationship } \\
\hline I & 90.4 & 90.4 \\
\hline II & 99.2 & 99.2 \\
\hline III & 99.9 & 99.9 \\
\hline IV & 100.0 & 100.0 \\
\hline Sum of all eigenvalues/total inertia & 1.000 & 1.000 \\
\hline Sum of all canonical eigenvalues & 0.200 & 0.224 \\
\hline Percentage of explained spore data variance & 20.0 & 22.4 \\
\hline
\end{tabular}

\begin{tabular}{|c|c|c|c|c|c|c|c|c|}
\hline \multirow[t]{2}{*}{ Variables } & \multicolumn{2}{|c|}{ Lambda A } & \multicolumn{2}{|c|}{ Explained data variance $(\%)$} & \multicolumn{2}{|l|}{ F-ratio } & \multicolumn{2}{|l|}{$p$ value } \\
\hline & Hourly & Daily & Hourly & Daily & Hourly & Daily & Hourly & Daily \\
\hline TEMP & 0.16 & 0.16 & 16 & 16 & 650.42 & 27.34 & 0.002 & 0.002 \\
\hline RH & 0.03 & 0.04 & 3 & 4 & 167.29 & 7.56 & 0.002 & 0.002 \\
\hline WIND & 0.01 & 0.02 & 1 & 2 & 19.97 & 3.06 & 0.002 & 0.002 \\
\hline PRECIP & 0.00 & 0.00 & 0.0 & 0.0 & 5.29 & 1.21 & 0.004 & 0.004 \\
\hline
\end{tabular}

agriculture, horticulture and forestry (pathogens, plant disease control), aerobiology (particles suspended in the air). In this article, the authors present impact of selected meteorological parameters on the content and composition of the widest possible in this study spectrum of airborne fungal spores, in terms of hourly 
and daily values, for 1 year. Due to the time-consuming process, not many authors described the hourly concentration of spores in the air, and the models are created mainly for selected days and only for one or two genus or spore groups. In one of such studies, taking into account the hourly values of the variables in the days, when the Alternaria and Cladosporium spore concentrations exceed threshold values, Grinn-Gofroń and Strzelczak (2009) applied, among others, Spearman's rank association test. Simple analysis revealed that relative humidity strongly and negatively influenced the concentration of Alternaria spores, and air temperature-strongly and positively $\left(r_{\mathrm{s}}=-0.657\right.$ and $r_{\mathrm{s}}=0.582$, respectively). Wind speed also significantly and positively influenced Alternaria spore concentration; however, it was weak correlation $\left(r_{\mathrm{s}}=0.290\right)$. Precipitation was not a statistically significant variable. Cladosporium spore concentration correlated less strongly with relative humidity and temperature $\left(r_{\mathrm{s}}=-0.314\right.$ and $\left.r_{\mathrm{s}}=0.290\right)$, and not significantly with wind speed and precipitation. In our study, the hourly concentrations of Alternaria and Cladosporium spores were similarly positively correlated with air temperature; however, the relation was stronger with Cladosporium than with Alternaria ( $r_{\mathrm{s}}=0.511$ and $r_{\mathrm{s}}=0.359$, respectively). As in the cited studies, relative humidity and precipitation negatively affect, and wind speed positively affects hourly concentrations of both types of spores, although the relationships were much weaker. In contrast, precipitation and wind speed significantly influenced the hourly concentrations of Alternaria and Cladosporium spores in our study (despite the fact that correlations are weaker, statistical significance is result of much higher number of samples).

The other similar study (Kasprzyk et al. 2011) showed that in the selected days, when the spore concentration exceeds threshold values, the relationships between hourly Ganoderma spore concentrations and meteorological variables differed in strength and direction between two cities located in two different climatic regions of Poland (maritime climate in Szczecin and continental climate in Rzeszów). In general, those dependencies were much weaker and mostly insignificant in Szczecin comparing to Rzeszów. Simple Spearman's rank correlation analysis revealed in Szczecin directly proportional, weak influence of temperature on the hourly Ganoderma spore concentration $\left(r_{\mathrm{s}}=0.010\right)$, as in our study $\left(r_{\mathrm{s}}=0.179\right)$. However, in the cited study it was not statistically significant dependence. Conversely, hourly Ganoderma spore concentrations were negatively and significantly correlated with temperature in Rzeszów $\left(r_{\mathrm{s}}=-0.320\right)$. A weak positive and insignificant correlation with relative humidity was observed by Kasprzyk et al. (2011) in Szczecin $\left(r_{\mathrm{s}}=0.030\right)$. Similarly, in our study it was a directly proportional, however statistically significant relationship $\left(r_{\mathrm{s}}=0.183\right)$. Closest relationship with relative humidity was observed in Rzeszów in the cited study $\left(r_{\mathrm{s}}=0.320\right)$. An inversely proportional impact was observed for wind speed-in Szczecin it was statistically insignificant (in our and cited studies), and in Rzeszów it was significant and weak $\left(r_{\mathrm{s}}=-0.190\right)$.

There are many articles on the influence of meteorological factors on the presence of spores in the air, taking into account daily values of variables and dependences between particular spore types and individual meteorological variables. Studies on the most allergenic spores of Cladosporium, Alternaria, Drechslera type, Ganoderma and Epicoccum revealed significant, positive correlation between daily mean spore concentration and daily mean air temperature (e.g., Troutt and Levetin 2001; Oliveira et al. 2009; Sadyś et al. 2015, 2016; Ianovici 2016; Ščevková et al. 2016). Generally, most airborne fungi are moderately temperature dependent- they tolerate neither too low nor too high temperature (Ingold 1971). In our study, simple analysis (Spearman's rank correlation test) revealed the strongest, directly proportional influence of air temperature on the daily spore concentration of Cladosporium, Ganoderma and Drechslera type. Other significant relationships were moderate $\left(r_{\mathrm{s}}<0.500\right.$ with Alternaria, Polythrincium, Tilletia, Torula) or weak $\left(r_{\mathrm{s}}<0.300\right.$ with Didymella, Pleospora, Chaetomium, Periconia and Epicoccum). Daily concentration of Stachybotrys spore was the only variable significantly and negatively influenced by temperature, but this type of spores is very rare, and this relationship can be accidental.

Many studies revealed negative correlation between relative humidity and daily concentration of "dry-weather spore types" in the air. Stępalska and Wołek (2005), Grinn-Gofroń and Mika (2008), Oliveira et al. (2009), Sadyś et al. (2015, 2016), Ianovici (2016) found such significant dependences in case of Cladosporium, Alternaria, Drechslera type, Epicoccum, Pithomyces, Polythrincium and Torula 
spores. Our study confirmed significant, inversely proportional relationships between relative humidity and the concentration of spores: moderate with Torula and Tilletia, and weak with Drechslera type. Furthermore, simple analysis revealed in our study significant, directly proportional, weak impact of relative air humidity on the daily spore concentration of Phaeosphaeria, Fusarium, Pleospora and Agrocybe.

The direction of correlation between precipitation and spore concentration in the air depends on the spore discharge mechanisms and "rain-out and wash-out effects." The strongest, directly proportional correlation with precipitation showed in our study the daily spore concentrations of Leptosphaeria type and Stemphylium $\left(r_{\mathrm{s}}=0.416\right.$ and $r_{\mathrm{s}}=0.300$, respectively). Sadyś et al. (2015) found the spores of Leptosphaeria type the only group that was strongly linked to rainfall. Unlike in our study, in the Sadyś et al. (2015) analyses this resulted in a further close positive association with relative humidity. GrinnGofroń and Mika (2008) showed changeable dominance between rainfall and relative humidity in relation to Leptosphaeria type spore fluctuation.

Knowledge of wind statistics is important for modeling the aerial transport and surface-atmosphere exchange of fungal spores. Statistically significant results of our simple analyses showed only inversely proportional impact of wind speed on the daily spore concentration of Ganoderma (moderate correlation), Chaetomium, Agrocybe and Epicoccum (weak correlation). Hasnain (1993) also revealed significant, negative relationship between wind speed and Ganoderma spore concentration. In the study of Ianovici (2016), in general, the daily concentrations of $A l$ ternaria, Cladosporium, Epicoccum and Pithomyces spores were negatively correlated with wind speed. Most of these relationships were significant and weak.

The impact of complex of meteorological factors on the composition of spores has been analyzed in only a few studies, taking into account the daily values of the variables. Li and Kendrick (1994) applied canonical correspondence analysis (CCA-for unimodal data structure) to assess the relative effects of multiple environmental factors on the composition of twenty identified fungal genera and some groups of unidentified to genus spores. They took into account 16 environmental factors, including 6 meteorological variables. In a whole year, according to the arrow lengths (visible on the ordination diagram), the most important explanatory variables were found to be: relative air humidity, rain, vegetation, cloud, temperature and wind speed, in descending order. The authors did not assess the ranges of the explained variation of the spore composition and the statistical significance of individual environmental variables in explaining the fungal spore variation in the air (no results of stepwise forward selection). According to the ordination diagram (for the whole of 1992), spore concentration of Leptosphaeria type responded to high relative humidity and similar as the Drechslera typeincreased during rain. Concentration of Alternaria spores decreased with rain and increased with temperature. Higher wind speed was positively related to the concentration of Periconia spores. CCA results (separate for February, May, August and December) revealed that the influence of some environmental factors on the airborne fungal spores varied with the season of the year.

In the next study on functional relationships of airborne fungi with meteorological factors, $\mathrm{Li}$ and Kendrick (1995) applied redundancy analysis (RDAfor linear data structure). For the whole of 1992, in accordance with the lengths of meteorological arrows (gradients), the ranking in descending order of importance was found to be: mean, minimum and maximum temperature, mean wind speed, relative humidity, rain, maximum wind speed and snow. Spore concentrations of most airborne fungal taxa were positively associated with air temperature. Epicoccum spore concentration was positively related with the wind speed. Spores of Leptosphaeria type showed a somewhat closer association with rain and relative humidity.

In our previous study (Grinn-Gofroń and Bosiacka 2015), we determined functional relationships between composition of airspora and meteorological factors using CCA (during a 4-year period and for each year separately). The CCA results indicated that all statistically significant variables accounted for $15.3 \%$ of the total variance in the spore data in the 4 years. The largest amount of the total variance was explained in this period by the mean air temperature (9.2\%). In a recent published aerobiological study using an ordination method (RDA), Sadyś et al (2015) examined the daily relationship between 10 spore types and 8 meteorological variables (for 5 years separately). They determined which factors favored the most abundance of spores in the air, and moreover, applied variance inflation factor to indicate which explanatory variables 
were auto-correlated and needed to be excluded from analyses. The authors, similarly to Li and Kendrick (1994, 1995), did not use stepwise forward selection. Meteorological parameters were classified in the descending order of importance based solely on the length of the arrows, visible on the ordination diagrams. Repetitive tendencies in all years were in general: directly proportional impact of relative humidity and rain on the daily concentration of Leptosphaeria type and Didymella spores, and air temperature-on the daily concentration of Alternaria spores.

Our presented study indicates that temperature, relative humidity, wind speed and precipitation, in that order of importance, significantly influenced composition of airborne spora, both in hourly and daily periods of time. The range of explained total variance in the spore data was, in general, similar as in our previous study (Grinn-Gofroń and Bosiacka 2015). Air temperature had the strongest impact on the content and composition of spores-many times greater than the impact of other factors. In the ordination diagram, the same as in studies of $\mathrm{Li}$ and Kendrick (1994, 1995), Sadyś et al. (2015) and GrinnGofroń and Bosiacka (2015), spores of Leptosphaeria type were related to the highest or moderate values of relative humidity and precipitation. In contrast to the cited studies, spores of Didymella showed no closer association with these variables. As in the study of Grinn-Gofron and Bosiacka (2015), the occurrence of Cladosporium, Alternaria and Drechslera type spores was associated with high temperature values. Such relationship between Alternaria spores and air temperature was also seen on the ordination diagrams in other cited studies (Li and Kendrick 1994, 1995; Sadyś et al. 2015), between Cladosporium spores and air temperature-in the study of $\mathrm{Li}$ and Kendrick (1995) and during some years-in the study of Sadyś et al. (2015). High, directly proportional impact of air temperature on the abundance of Ganoderma spores, visible in our presented RDA diagram (for daily data set), confirms the results achieved by Sadyś et al. (2015) in 1 of 5 years studied.

Basic meteorological parameters are useful in determining spore content and composition in the air, but the modeling of hourly data needs some further elaboration. Averaging the spore concentration into daily mean values smooths the relationship and enhances the performance of daily models. Therefore, hourly variations in spore abundance are much difficult to explain by meteorological parameters comparing to the overall daily sum of spores in the air. The results of Spearman's rank association test and multivariate direct gradient analysis for hourly data in our presented study were of lower performance compared to these for daily data set. The primary reason is likely that the hourly spore concentrations fluctuate considerably, while most of the meteorological parameters remain rather stable in such a period of time. Key factors in hourly prediction of spore concentration and composition may be, for example, wind characteristics. The problem still demanding solutions in aerobiological studies is "isokinetic problem": wind speed may fluctuate hour by hour, minute by minute, while the trap' flow rate of air remains constant at a fixed speed resulting in two possibilities_-sample speed exceeds air speed or air speed exceeds sample speed (Hirst 1952, 1953; Hasnain 1993). Further studies are needed to reveal additional parameters which could increase the accuracy of models for hourly spore contents.

Open Access This article is distributed under the terms of the Creative Commons Attribution 4.0 International License (http:// creativecommons.org/licenses/by/4.0/), which permits unrestricted use, distribution, and reproduction in any medium, provided you give appropriate credit to the original author(s) and the source, provide a link to the Creative Commons license, and indicate if changes were made.

\section{References}

BAF (British Aerobiology Federation). (1995). Airborne pollens and spores. A guide to trapping and counting (1st ed.). Rotherham: Natl Pollen \& Hay-fever Bur.

Carlile, M. J., Watkinson, S. C., \& Gooday, G. W. (2001). Spores, dormancy and dispersal. In M. J. Carlile, S. C. Watkinson, \& G. W. Gooday (Eds.), The fungi (2nd ed., pp. 183-243). London: Academic Press.

Elbert, W., Taylor, P. E., Andreae, M. O., \& Pöschl, U. (2007). Contribution of fungi to primary biogenic aerosols in the atmosphere: Wet and dry discharged spores, carbohydrates, and inorganic ions. Atmospheric Chemistry and Physics, 7(17), 4569-4588.

Frenguelli, G. (2003). Basic microscopy, calculating the field of view, scanning the slides, sources of error. Postepy Dermatologii i Alergologii, 20, 227-229.

Grinn-Gofroń, A., \& Bosiacka, B. (2015). Effects of meteorological factors on the composition of selected fungal spores in the air. Aerobiologia, 31(1), 63-72.

Grinn-Gofron, A., \& Mika, A. (2008). Selected airborne allergenic fungal spores an meteorological factors in Szczecin, Poland, 2004-2006. Aerobiologia, 4, 89-97. 
Grinn-Gofroń, A., \& Strzelczak, A. (2009). Hourly predictive ANN and MRT models of Alternaria and Cladosporium spore concentrations in Szczecin (Poland). International Journal of Biometeorology, 53, 555-562.

Hasnain, S. M. (1993). Influence of meteorological factors on the airspora. Grana, 32, 184-188.

Hirst, J. M. (1952). An automatic volumetric spore trap. Annals on Applied Biology, 39, 257-265.

Hirst, J. M. (1953). Changes in atmospheric spore content: Diurnal periodicity and the effects of weather. Transactions of the British Mycological Society, 36(4), 375-IN8.

Hjelmroos, M. (1993). Relationship between airborne fungal spore presence and weather variables. Grana, 32, 40-47.

Ianovici, N. (2016). Atmospheric concentrations of selected allergenic fungal spores in relation to some meteorological factors, in Timisoara (Romania). Aerobiologia, 32, 139-156.

Ingold, C. T. (1971). Fungal spores. Their liberation and dispersal. Oxford: Clarendon Press.

Ingold, C. T. (1999). Active liberation of reproductive units in terrestrial fungi. Mycologist, 13(3), 113-116.

Kasprzyk, I., Grinn-Gofroń, A., Strzelczak, A., \& Wolski, T. (2011). Hourly predictive artificial neural network and multivariate regression trees models of Ganoderma spore concentrations in Rzeszów and Szczecin (Poland). Science of the Total Environment, 409, 949-956.

Lacey, J. (1986). Water availability and fungal reproduction: Patterns of spore production, liberation and dispersal. In P. G. Ayres \& L. Boddy (Eds.), Water, fungi and plants (pp. 65-86). Cambridge: Cambridge University Press.

Li, D. W., \& Kendrick, B. (1994). Functional relationships between airborne fungal spores and enviromental factors in Kitchener-Waterloo, Ontario, as detected by Canonical correspondence analysis. Grana, 33(3), 166-176.

Li, D. W., \& Kendrick, B. (1995). A year-round study on functional relationships of airborne fungi with meteorological factors. International Journal of Biometeorology, 39, 74-80.
Meredith, D. S. (1963). Violent spore release in some fungi imperfecti. Annals of Botany, 27, 39-47.

Money, N. P. (2015). Spore production, discharge and dispersal. In S. C. Watkinson, L. Boddy, \& N. P. Money (Eds.), The fungi (3rd ed., pp. 67-98). London: Academic Press.

Oliveira, M., Ribeiro, H., Delgado, J. L., \& Abreu, I. (2009). The effects of meteorological factors on airborne fungal spore concentration in two areas differing in urbanization level. International Journal of Biometeorology, 53, 61-73.

Pringle, A., Patek, S. N., Fischer, M., Stolze, J., \& Money, N. P. (2005). The captured launch of a ballistospore. Mycologia, 97(4), 866-871.

Sadyś, M., Adams-Groom, B., Herbert, R. J., \& Kennedy, R. (2016). Comparisons of fungal spore distributions using air sampling at Worcester, England (2006-2010). Aerobiologia, 32(4), 619-634.

Sadyś, M., Strzelczak, A., Grinn-Gofroń, A., \& Kennedy, R. (2015). Application of redundancy analysis for aerobiological data. International Journal of Biometeorology, 59, 25-36.

Ščevková, J., Dušička, J., Mičieta, K., \& Somorčík, J. (2016). The effects of recent changes in air temperature on trends in airborne Alternaria, Epicoccum and Stemphylium spore seasons in Bratislava (Slovakia). Areobiologia, 32, 69-81.

Statsoft Inc. (2011). Statistica (data analysis software system), v. 10.0. www.statsoft.com.

Stępalska, D., \& Wołek, J. (2005). Variation in fungal spore concentration of selected taxa associated to weather condition Cracow, Poland, in 1997. Aerobiologia, 21, 43-52.

ter Braak, C. J. F., \& Šmilauer, P. (2002). CANOCO reference manual and user's guide to Canoco for windows.

Troutt, C., \& Levetin, E. (2001). Correlation in spring spore concentrations and meteorological conditions in Tulsa, Oklahoma. International Journal of Biometeorology, 45, 64-74. 